\title{
VIDA, TRABALHO E FORMAÇÃO COMO ELEMENTOS DA CONSTRUÇÃO DA IDENTIDADE LEITORA DOS PROFESSORES DA EDUCAÇÃO BÁSICA
}

\begin{abstract}
Elisangela André da Silva Costa ${ }^{1}$
Maria Socorro Lucena Lima

Resumo. Este estudo aborda a construção da identidade leitora de professores, partindo de elementos relacionados à vida, à formação e ao trabalho, que dialeticamente interferem neste processo. O objetivo geral foi compreender como, e a partir de que referenciais, são desenvolvidas as práticas de leitura dos professores nos anos iniciais do Ensino Fundamental. Metodologicamente optou-se pela pesquisa-ação crítico- colaborativa. Os resultados apontam para práticas profissionais e experiências formativas de leitura limitadas e limitantes por parte dos investigados.
\end{abstract}

Palavras-chave. Formação. Professores. Identidade. Leitura.

\section{LIFE, WORK AND TRAINING AS ELEMENTS OF THE CONSTRUCTION OF READING IDENTITY OF TEACHERS OF BASIC EDUCATION}

\begin{abstract}
This study deals with the construction of teacher reading identity, starting from elements related to life, training and work, which dialectically interfere in this process. The general objective was to understand how, and from which references, the teachers' reading practices were developed in the initial years of Elementary School. Methodologically we chose collaborative critical action research. The results point to professional practices and limited and limiting formative reading experiences on the part of the investigated ones.
\end{abstract}

Keywords. Training. Teachers. Identity. Reading.

\footnotetext{
${ }^{1}$ Universidade da Integração Internacional da Lusofonia Afro-Brasileira, Acarape - Ceará - Brasil, Doutora em Educação pela Universidade Federal do Ceará, Professora Adjunta, E-mail: elisangelaandre@unilab.edu.br.

${ }^{2}$ Universidade Estadual do Ceará, Fortaleza - Ceará - Brasil, Doutora em Educação pela Universidade de São Paulo, Professora Adjunta, E-mail: socorro_lucena@uol.com.br.
} 


\section{Introdução}

O presente estudo trata das práticas de leitura dos professores que atuam nos anos iniciais do Ensino Fundamental, considerando os diferentes tempos, espaços e atividades que vêm possibilitando aos mesmos o contato com o ato de ler.

Compreendemos que a democratização do acesso à escola, desencadeada no final do sec. XX, trouxe para o espaço escolar milhões de crianças pertencentes a famílias que historicamente foram excluídas do processo de escolarização. O resultado desse processo é uma crise na identidade da escola, decorrente da alteração do referencial cultural já instituído, fato que aponta para a necessidade de reorganização políticopedagógica, considerando essa nova realidade e os sujeitos que passam a fazer parte de seu cotidiano.

A partir dos efeitos dessa mudança social sobre as práticas pedagógicas, indagamos: como os professores dos anos iniciais do Ensino Fundamental compreendem, desenvolvem e avaliam suas práticas de leitura? O reconhecimento do professor como sujeito e de seu trabalho como práxis nos fez optar metodologicamente pela pesquisa-ação crítico- colaborativa, que pressupõe um processo de interação entre universidade e escola, mediado pela problematização das práticas, que promove o desvelamento da realidade e a (re) construção de conhecimentos sobre o processo educativo, sobre a formação do professor e sobre a função social da escola e da universidade.

O objetivo geral desta pesquisa foi compreender como, e a partir de que referenciais, são desenvolvidas as práticas de leitura dos professores nos anos iniciais do Ensino Fundamental. Para tanto, articulamos os referenciais teóricos de Freire (1995 e 1996); Zaponne (2001); Lima (2001 e 2004); Lajolo (2005); Dione (2008) e Barbier (2002), entre outros, aos dados coletados no campo através da interação com os sujeitos. Os resultados apontam para práticas profissionais e experiências formativas de leitura limitadas e limitantes por parte dos investigados. Porém, elementos presentes em seus discursos revelaram mudanças de perspectiva na forma como compreendem o ato de ler, agora associado à leitura crítica da realidade. 


\section{Contextualizando o Campo}

A presente pesquisa teve como locus de investigação uma escola da rede pública de ensino do município de Lavras da Mangabeira/Ce, marcada por baixo desempenho no Índice de Desenvolvimento da Educação Básica (IDEB) e nos processos de avaliação externa, como Sistema Permanente de Avaliação da Educação Básica do Ceará (SPAECE). Além das dificuldades enfrentadas pela escola, a definição do locus levou em consideração a abertura do grupo de professores e gestores à realização de um estudo desta natureza.

A escola contava, no período da pesquisa, com 320 alunos matriculados no Ensino Fundamental. A equipe escolar apontava como principais dificuldades encontradas no desenvolvimento de suas atividades a indisciplina, o pouco envolvimento dos pais, o desinteresse dos alunos e, ainda, situações que envolviam questões socioeconômicas da comunidade, como a evasão escolar, resultante do êxodo das famílias da localidade em busca de melhores condições de vida em outros locais.

Como potencialidades eram apontadas: o quadro de profissionais qualificados, existência de espaço físico para o desenvolvimento das atividades dos professores (salas de aula amplas, biblioteca, pátio e sala de multimeios, não reduzindo o processo educativo às aulas convencionais); recursos audiovisuais disponíveis e em bom estado, acervo de livros literários e assinatura de jornais e núcleo gestor constituído (compartilhando entre diretora, coordenadora pedagógica e secretária escolar as atividades de ordem administrativa, financeira e pedagógica).

Analisando o perfil dos dez sujeitos envolvidos na pesquisa, identificamos como pontos convergentes em suas histórias: a escolarização básica concluída em instituições públicas; participação em Programas Especiais de formação profissional de professores desenvolvidos pelo Estado do Ceará e significativa experiência profissional como docente, apresentando em média nove anos de profissão. Tais questões expressam experiências comuns que, somadas a questões de ordem subjetiva, resultam em leituras diferentes da realidade. 
A pesquisa adentrou nesse espaço com a perspectiva de colaborar para o desvelamento dos fatores que se configuravam como entraves ao desenvolvimento dos hábitos de leitura por alunos e professores, sem esquecer que tais práticas se inserem em um contexto político-pedagógico mais amplo.

\section{O Caminho metodológico}

Nosso caminhar pela educação, na condição de professoras e pesquisadoras, tem nos impulsionado continuamente a compreender o processo de pesquisa como possibilidade de transformação das realidades sociais, a partir de um olhar crítico que desvele as questões que se encontram nos planos do não dito, ou do não visto. Tal compreensão nos motivou a buscar uma modalidade investigativa que se integrasse a um processo de autoconhecimento, que possibilitasse mudanças nos sujeitos e, consequentemente, na instituição envolvida. Nesse sentido, nos inspiramos na pesquisa-ação, extraindo como principal referência desta o compromisso com a mudança de práticas, inspirado nas descobertas e tomadas de consciência, desencadeadas no decorrer pesquisa, pelo grupo de pessoas nela implicadas.

Trazer o sentido das mudanças para o âmbito da percepção e da implicação dos professores significa colaborar para o desenvolvimento profissional e para a autonomia dos mesmos, fato que, de acordo com Franco (2001), não tem se apresentado no contexto das pesquisas em educação, que de um modo abrangente têm gerado como resultados de suas opções epistemológicas o distanciamento contínuo entre pesquisa educacional e prática educativa e a imobilização das equipes escolares frente ao contexto de medidas e iniciativas que chegam a este espaço.

A pesquisa-ação colaborativa, assim, surge como possibilidade de ressignificação dos conhecimentos que as pesquisas em educação têm formulado, tanto para os pesquisadores (como alternativa epistemológica para construção de uma elaboração científica mais próxima das práticas 
escolares) e para os professores (como melhor compreensão das teorias educacionais e maior articulação entre estas e a profissão).

A compreensão, a reflexão e a transformação das práticas são elementos fundamentais deste tipo de pesquisa. Cabe, nesse contexto, compreendermos que a acepção de prática que tomamos como referencial no desenvolvimento desta pesquisa é a que rompe com a compreensão tradicional que a liga ao tecnicismo, reduzida a uma sucessão de procedimentos elaborados com vistas ao repasse de informações aos alunos ou à reprodução de uma cultura institucional. Pensamos, antes, a prática na perspectiva apresentada por Franco (2008, p. 34), compreendida como a manifestação das associações e dos embates que envolvem questões institucionais; questões inerentes ao sujeito, suas crenças e valores; e questões que envolvem o contexto social, econômico, político e cultural com suas crenças e valores. É, portanto, considerada práxis transformadora (VAZQUEZ, 1977), associada à figura do professor como um intelectual crítico, historicamente situado, que reflete sobre sua prática e sobre as determinantes que a perpassam, visando à construção de novos modos de pensá-la e manifestá-la.

Nossa aproximação inicial com o campo se deu por meio da realização de um estudo exploratório que objetivou aumentar nossa compreensão acerca do tema estudado (SEVERINO, 2000), através de leituras relacionadas à formação de professores e a leitura, que se constituíram inicialmente como categorias mais amplas do trabalho a ser desenvolvido, articuladas a informações sobre o campo de pesquisa, no qual consideramos a escola, sua organização, os indicadores, as características socioeconômicas e culturais da comunidade escolar, entre outras questões que nos possibilitassem uma melhor compreensão do contexto no qual adentrávamos.

A partir deste levantamento inicial, foi programado e desenvolvido processualmente o cronograma de encontros de reflexão sobre a prática, voltado aos profissionais da escola, no decorrer de um período letivo, visando à problematização das práticas escolares, com ênfase naquelas que se referiam à leitura, coletando, de forma contextualizada, depoimentos referentes à vida, à formação e às práticas de leitura dos professores. 
A organização dos encontros privilegiou alguns pontos de partida, como: o entendimento do professor como pessoa (NÓVOA, 1995), que nos mobilizou a considerar as referências pessoais e profissionais como elementos fundamentais para a compreensão das posturas desses sujeitos diante das diferentes questões abordadas; o reconhecimento do professor como pesquisador (ELLIOT, 1990; STENHOUSE, 1987), ponto a partir do qual os espaços da sala de aula e da escola foram evidenciados como campos que possibilitam a construção do conhecimento acerca da docência, que por sua vez proporcionam a autonomia desse profissional em relação ao desenvolvimento do currículo; a compreensão do professor como profissional (IMBERNÓN, 2002) preparado para lidar, através do desenvolvimento de capacidades reflexivas e da autonomia, com a mudança e a incerteza presentes no contexto da contemporaneidade; e da compreensão do professor como profissional reflexivo (SCHON, 1992), que toma a sua prática, associada a elementos teóricos, como elemento de relevante importância no quadro de desenvolvimento da docência.

Nossa função como pesquisadoras foi bastante complexa, pois envolveu duas tarefas distintas e simultâneas: atuar no processo de formação de professores e registrar este, e outros processos observados na escola ou comunidade, de forma que os mesmos se constituíssem uma fonte privilegiada de informações. Nesse sentido, utilizamos a filmagem como uma importante estratégia de coleta de dados, que assumiu duas vertentes distintas: a elaboração da série conversas (trabalho que buscou levar, em forma de vídeo, a colaboração de pesquisadores da universidade para enriquecimento das discussões acerca das temáticas estudadas na pesquisa); e a produção de vídeos sobre a pesquisa (nos quais registramos elementos presentes no desenvolvimento da investigação, para socialização em grupos de estudo da universidade).

No que se refere ao processo de observação, não nos detivemos ao espaço específico da sala de aula, procurando atuar em espaços de socialização dos profissionais (sala de professores), espaços de socialização dos alunos (biblioteca) e atividades que envolvessem a comunidade local, para perceber quais eram os materiais de leitura disponíveis e como os mesmos 
eram utilizados nestes espaços. Nesse sentido, nos implicamos como observadores participantes, situados dentro e fora do grupo simultaneamente, sendo capazes de vivenciar, como membros do grupo, o desenrolar dos fenômenos e, ao mesmo tempo, problematizá-los (BARBIER, 2002).

Realizamos levantamento e análise documental, verificando nos projetos, planos e registros de atividades desenvolvidas por professores e profissionais, elementos que fundamentavam o trabalho em torno da leitura nos diferentes espaços escolares (sala de aula, laboratório de informática e biblioteca). Tal análise consistiu no desvelamento das ideias e concepções expressas nos registros por meio de tratamento analítico que possibilitou produzir inferências desses textos que, embora específicos, relacionam-se ao contexto social, de maneira objetivada (BAUER, 2002).

Por fim, destacamos a produção de relatos autobiográficos pelos professores, evidenciando aspectos relacionados às suas experiências pessoais e profissionais que se articulavam de forma mais direta às temáticas abordadas no decorrer dos encontros de reflexão sobre a prática. De acordo com Nóvoa (1995), o acesso às histórias dos sujeitos nos possibilita a compreensão das formas como os mesmos, ao longo do tempo, construíram suas identidades.

O exercício de buscar, na realidade, elementos para formulação de questões e reflexões é árduo e requer um movimento dialético de percepção de si e do outro, da escola e do sistema educacional mais abrangente, das práticas individuais e coletivas, entre outras tantas questões. Assim, a triangulação das diferentes estratégias utilizadas possibilitou olhar para escola de forma mais aguçada e crítica, zelando pelos critérios de cientificidade próprios das atividades de pesquisa.

\section{A Leitura do mundo, da palavra e da profissão}

O desenvolvimento da leitura enquanto prática social é um tema que nos convida a rever a gênese do desenvolvimento da linguagem pela humanidade, uma vez que a elaboração do código escrito é posterior a outras 
formas de comunicação que envolvem tanto a leitura, quanto a expressão do mundo pelo homem.

A abordagem histórica da leitura relaciona-se à compreensão dos planos genéticos de desenvolvimento humano postulados por Vygotsky (1987), que considera quatro entradas que, juntas, caracterizariam o funcionamento psicológico do homem, a saber: Filogênese (referente à história da espécie humana); Ontogênese (relacionada à história do indivíduo da espécie); Sociogênese (correspondente à história do meio cultural no qual o sujeito está inserido) e a Microgênese (que diz respeito ao aspecto mais microscópico do desenvolvimento, situado em cada indivíduo). Todas as aprendizagens, portanto, não se referem somente a um processo que se inicia e se encerra pela vivência de cada sujeito, mas ao acúmulo das possibilidades tanto biológicas, quanto sociais, que cada indivíduo herda de sua espécie para projetar-se além do já instituído.

Na história da leitura de cada um de nós, portanto, está circunscrita a história da leitura de nossa comunidade e de nossa espécie, desde os tempos mais longínquos. Constitui-se como uma forma de expressão das descobertas feitas pelo homem e que se renovam na medida em que cada um de nós nasce para o mundo e para as relações que se estabelecem nele através da linguagem (GOMES, 2009).

Movida pela crescente necessidade de comunicação, a humanidade buscou promover a expressão de fatos, ideias, crenças e valores utilizando recursos variados, como a transmissão oral da tradição, o uso de rituais e da dança, o apelo às artes visuais, entre outros (ZILBERMAN, 2000). Assim, verificamos uma importante marca da evolução da leitura, que coloca o homem não só como decodificador dos sinais da natureza, mas codificador de suas experiências pessoais. Dessa maneira, observamos que as possibilidades de leitura do mundo foram sendo modificadas na medida em que se desenvolveram as formas mais elementares de registro, até se chegar à elaboração de um código escrito mais complexo, que possibilitou à humanidade uma nova forma de relacionamento com o tempo, colaborando para o estabelecimento de pontes entre as experiências humanas em 
diferentes épocas, utilizando o passado para compreender melhor o presente e para projetar o futuro.

Visualizamos, assim, um importante elemento de reflexão sobre a leitura da palavra como uma prática social excludente, que é a transformação gradativa da linguagem não verbal em verbal, e da linguagem verbal em código escrito, que passa a se configurar como uma das principais vias de acesso do homem ao conhecimento e à informação, fato que historicamente não se estendeu a todos, mas a parcelas da população que se beneficiaram dessa condição. A leitura de mundo, portanto, não é ato neutro, tampouco habilidade que se desenvolve espontaneamente. A leitura é ato curioso de desvelamento do mundo, é fruto de questionamento sobre a natureza e os fundamentos das coisas e dos fenômenos que nos rodeiam. Assim, não é mera decodificação, situa-se na seara da construção de sentidos e significados que envolvem o homem, a sua história e sua experiência. Anuncia possibilidades de transformação na forma de cada um perceber a si, a sua história e os tipos de relação que o envolvem na sociedade, modificando não só a sua forma de perceber, mas de agir no mundo.

Acreditamos que a reflexão sobre a leitura, suas possibilidades e limitações, necessita passar pela análise histórica e dialética das instituições que a promovem, compreendendo-as como espaços sociais encharcados por compreensões de mundo e interesses distintos, e por que não dizer antagônicos. Cabe, portanto, a cada educador estabelecer reflexões acerca dos princípios e finalidades do processo educativo, tentando compreendê-los em um quadro mais abrangente, que coloca a escola como um espaço voltado para a formação, para a socialização dos saberes constituídos pela humanidade e para a humanização e emancipação do próprio homem.

Zappone (2001), através de pesquisa sobre as principais abordagens de leitura em circulação no Brasil, agrupou as principais referências utilizadas pelos pesquisadores do assunto em quatro linhas distintas: linha políticodiagnóstica (em que ler é engajar-se politicamente); linha cognitivo-processual (em que ler é interagir com o texto); linha discursiva (em que ler é construir significado) e linha estruturalista (em que ler é decodificar). Cada uma dessas linhas apresenta características diferenciadas que implicam modos distintos 
de tratamento didático do texto e da leitura pelos profissionais que trabalham com o ensino, que vão desde uma postura mais passiva a uma postura mais ativa e crítica diante do texto e da linguagem.

No contexto atual, em que as relações de desigualdade encontramse cada vez mais veladas pelos discursos da aparente igualdade de oportunidades, ressaltamos que a compreensão do leitor como um sujeito historicamente situado, capaz de ler criticamente seu mundo, compreender e se posicionar diante das ideias expressas pelos mais variados veículos de comunicação é aquela que pode contribuir para a constituição de um novo horizonte na compreensão do homem enquanto ser social.

Neste contexto a reflexão acerca dos trajetos formativos dos docentes ganhou espaço e importância nessa investigação, pois se constituiu como referência para identificação dos limites gerados por uma formação desvinculada da leitura da vida e da leitura do trabalho, delimitando novos pontos de partida para uma compreensão mais abrangente e existencial de si, enquanto sujeito de sua história e cooperador da escrita das histórias de seus educandos. Assim se evidencia a importância de refletir sobre o processo de formação dos professores.

Ao realizar uma leitura crítica da própria formação, dos contextos de atuação profissional e da constituição da identidade, os professores têm a capacidade de reconhecer o estatuto epistemológico de cada um desses elementos e compreendê-los como oportunidades de alargamento (ou não) de sua visão de mundo e de profissão. Afinal de contas é necessário compreender: o que e como podemos aprender com nossa formação? O que e como podemos aprender com o nosso trabalho? $\mathrm{O}$ que e como podemos aprender com nossa vida?

O produto desses questionamentos é um saber novo, situado e pleno de sentido. É saber construído na relação dialética do escrito com o vivido; do eu com o outro; do plural com o singular; do objetivo com o subjetivo; entre outras tantas relações possíveis. É síntese (provisória) de uma práxis criadora (VAZQUEZ, 1977), em que os conhecimentos gerados por práxis anteriores são convertidos em uma nova práxis, que auxilia cada sujeito a buscar alternativas de atuação diante das novas necessidades e situações que surgem 
cotidianamente. Assim, temos uma interessante articulação entre a capacidade que cada sujeito tem de ler a realidade e a capacidade que cada sujeito tem de escrever uma nova página em sua história e na história de sua profissão.

Compreendemos que os processos formativos devam cumprir exatamente a finalidade de estabelecer novas formulações acerca do trabalho docente. Nesse sentido, as teorias existentes são de extrema importância, pois se constituem como referências para a análise de situações relacionadas às diferentes dimensões do processo educativo - ética, política, técnica e estética (RIOS, 2008). No entanto, é necessário aos formadores que utilizem tais teorias de forma exploratória, buscando desvelar a visão de mundo que está por trás das ideias expressas; situar o teórico enquanto sujeito em um tempo histórico específico, entre outras questões que permitam compreender os limites e as possibilidades que fazem do conhecimento nela expresso algo inacabado e que pode, portanto, ser contestado, complementado, contextualizado ou ressignificado por outros estudiosos, categoria na qual se inserem os próprios professores.

É preciso que sejamos capazes de ler nas entrelinhas das propostas de formação suas verdadeiras finalidades e o lugar que o professor, seus saberes, sua vida e seu trabalho ocupam no interior de cada uma delas. Uma boa leitura do mundo e da profissão é aquela que serve de trampolim para outras leituras, para outros horizontes e não aquela que nos prende em uma estrutura que se compreende fechada, acabada, repetitiva e com interpretações restritas e restritivas.

Nossa identidade como leitores é um processo histórico e, portanto, inacabado, sujeito a transformações. É metamorfose que implica não só na forma de ler o mundo, mas de atuar no mundo. É transformação do olhar e transformação de nós mesmos. É, ao mesmo tempo, instrumento e produto de formação. É nesse sentido que ganha importância a discussão acerca da construção identitária do professor como leitor. 


\section{Construção da identidade leitora dos professores}

A história dos professores implicados na pesquisa trazia marcas das condições de acesso à escola vivenciadas pela população brasileira até meados de 1990. A conjugação de prédios inadequados e professores sem a devida qualificação, materiais didáticos escassos e limitados, entre outros elementos, determinaram o desenvolvimento de uma proposta educativa com sérias limitações (VIEIRA; FREITAS, 2003).

Resultados de tais fatos são evidenciados pelos professores ao serem indagados acerca de como teriam sido apresentados à leitura. Suas respostas revelam diferentes elementos da história da educação brasileira, presentes não só no contexto da pesquisa, mas generalizáveis a outros espaços, como:

- Entrada tardia das crianças na escola - "Eu já fui alfabetizada em casa. Só que eu tinha o sonho de ir para a escola, ali onde é a creche hoje. Sempre eu pedi a minha mãe para ir, mas como eu morava no sítio era difícil o acesso né?" (P9);

- Processo de alfabetização desenvolvido nas próprias casas por familiares que já dominavam esse processo - "Eu fui alfabetizado em casa por uma tia, que era uma mulher muito sábia. Quando cheguei na escola, já sabia ler e escrever. E não acho que isso tenha sido ruim" (P5);

- Salas multisseriadas com crianças em diferentes etapas de desenvolvimento - "Eu me lembro que a professora juntava um monte de menino lá na casa dela para poder ensinar. Quando a gente terminava o ano, ia repetir de novo porque não tinha para onde ir" (P9);

- Utilização de cartilhas e cartas de $A B C$, que tinham na repetição e na memorização suas principais utilidades;

- Castigos físicos ilustrados através da utilização de palmatórias - "Eu fui alfabetizada naquele modelo das famílias silábicas, que a gente 
tinha de decorar pra poder dizer pra professora e quem não soubesse era palmatória na certa" (P7).

Observamos que a leitura de outros materiais, com exceção da cartilha e da carta do $\mathrm{ABC}$, foi relatada por apenas uma professora, revelando que o processo de alfabetização vivenciado pela maioria dos professores baseava-se na repetição e memorização de unidades menores (letras e sílabas) para posterior composição de unidades maiores (palavras, frases e textos), sendo concebido como única porta de entrada para a interação com o universo da leitura, que só poderia ser vivenciada após o domínio do código escrito (FREIRE, 1992). Até que o processo se consolidasse, as únicas leituras possíveis eram aquelas que instrumentalizavam a memorização das famílias silábicas, como Ivo viu a uva.

A história destes professores, como leitores, decorre de uma visão de alfabetização como processo de prontidão para a entrada no mundo da leitura, muito presente no país até meados de 1980. Da perspectiva de linguagem como um sistema fechado, da qual decorre o método de alfabetização vivido pelos professores, organizou-se grande parte das práticas de leitura nos diferentes níveis de ensino, que consistiam na mistificação da palavra escrita, abordada autoritariamente redundando, de acordo com Silva (2008), numa docilização dos estudantes. Segundo o autor os principais efeitos negativos dessa organização sobre o processo formativo dos alunos se relacionam a posturas passivas, submissas e obedientes em relação aos textos; a redução das expectativas do leitor, a memorização e a reprodução de ideias em detrimento de questões relacionadas ao processo de construção ativa de conhecimentos; a abordagem reducionista dos elementos textuais e contextuais, que favorecem a construção de uma identidade leitora passiva.

Assim, não é difícil encontrar professores com dificuldade de expressar suas próprias opiniões acerca de textos que circulam socialmente, por não conseguirem realizar o exercício de considerar alguns elementos importantes para a compreensão mais ampla deles, como: quem é o autor e em que contexto escreveu? Qual o objetivo do texto? Que mensagens estão nas entrelinhas? Que visão de mundo sustenta o desenvolvimento do 
conteúdo? Ou seja, questões que associam a produção de um enunciado a uma construção histórica e social (BAKHTIN, 1988).

As metodologias vivenciadas pelos professores no processo de escolarização inicial evidenciam como as práticas que fragmentam a linguagem e, por consequência, o saber e o próprio ser humano eram comuns. Quando questionados acerca das metodologias de leitura vivenciadas na infância, destacaram elementos relacionados a "rituais de repetição", “decoreba”, “soletração", entre outros desta natureza.

Verificamos que a vivência dos professores em relação à leitura foi ao mesmo tempo limitada, em decorrência das condições em que foram escolarizados (métodos inadequados, falta de condições materiais e limitação da formação do próprio professor) e limitante, pois reduziram o ato de ler a uma decodificação desligada do mundo, da cultura, da reflexão crítica, aprisionando o leitor às páginas de um texto, em uma abordagem estruturalista.

Além dos limites encontrados nas condições acima apresentadas, destacamos, ainda, a dificuldade de acesso a livros no decorrer da infância. Quando consultados acerca dessa questão quatro (4) professores afirmaram ter oportunidade de ler (ou ouvir) alguma obra literária no decorrer da infância; ao passo que esse número aumenta na adolescência para seis (6). Já na fase adulta, verificamos uma continuidade na tendência de aumento do percentual ligado àqueles que conseguiram obter, de alguma forma, acesso a livros, registrando nove (9) professores, o que simboliza um maior acesso a esse tipo de material escrito.

A biblioteca da Escola onde foi desenvolvida a pesquisa tinha um bom acervo, composto por obras voltadas tanto à informação, quanto à fruição, adquiridas através do Plano Nacional da Biblioteca Escolar - PNBE. Apesar de ser um espaço aberto para empréstimos a professores, alunos e funcionários, verificamos, ao consultar os professores acerca dos livros lidos no período da pesquisa, que todos têm o hábito de tomar livros emprestados, no entanto, apenas seis dos dez professores consultados recorriam à biblioteca da escola. Um fato que se relaciona, também, à falta de formação do profissional que lá atuava para implementação das atividades de leitura 
nesse espaço, e passível de generalização, se tomarmos como referência a análise realizada pelo próprio Ministério da Cultura como um elemento que dificulta o desenvolvimento da política de leitura no país (BRASIL, 2006).

A construção da identidade leitora dos professores, como pudemos observar no decorrer dessa reflexão, vem sendo construída em meio a relações sociais historicamente desiguais que afetam as condições de acesso ao livro e à leitura, contribuindo muito mais para um processo de alienação que de emancipação humana.

Destacamos, no entanto, o caráter dialético dessa construção, que compreende o limite e a possibilidade, a reprodução e a transformação, o futuro e o por vir. A escrita de uma nova história e a formulação de novas identidades leitoras é possível, se tomarmos os ensinamentos de nossa própria construção identitária como elementos que nos ajudem a refletir sobre o que é possível fazer, mas também sobre o que é aparentemente impossível, mas necessário.

É nesse campo de contradições e de limites que os professores desenvolvem suas práticas de leitura enquanto profissionais. Os saberes da experiência ligados às limitações que impediram esses sujeitos de constituir uma leitura mais crítica da realidade, associados à compreensão da leitura como apropriação das mensagens emitidas pelos autores e identificação uma única interpretação possível, podem ser identificadas como as principais marcas das atividades que estes profissionais desenvolviam em sala.

A partir dos estudos realizados, os professores colaboradores foram desvelando a implicação que as questões de ordem social, política, econômica e ideológica têm no ato de ler. Essa tomada de consciência os fez perceber o quanto precisavam caminhar para construir práticas que possibilitassem aos seus alunos a capacidade de questionar, de duvidar, de complementar e de reconstruir significados para os textos que leem em sala de aula.

Consultando os professores acerca das principais limitações de seu trabalho com a leitura em sala de aula verificamos elementos como a falta de interesse dos alunos (apontada por seis professores); a falta de acompanhamento da família (citada por quatro professores); a falta de apoio da escola, a dificuldade em lidar com a associação entre a leitura e a disciplina 
que leciona e a falta de tempo para realizar leituras (cada um citado uma única vez).

Ao indagarmos sobre as estratégias utilizadas para superação das dificuldades apontadas identificamos ações relacionadas à vivência cotidiana de atividades de leitura (destacada por quatro professores); os conhecimentos acerca da docência, proporcionados pelos cursos e vivências profissionais (citados por três professores); o gosto pela leitura por parte do professor (mencionado por dois professores); a problematização dos conteúdos e a existência de recursos materiais (citado uma vez, cada um).

A partir do contato sistemático com o cotidiano da escola, verificamos que ora os professores conseguiam alinhar aspectos do discurso com os aspectos vivenciados em sala de aula, ora não. É justamente por esta questão que ganha importância a necessidade de refletir sistematicamente sobre a prática que desenvolvemos.

Sabemos que o tempo de realização dessa pesquisa foi insuficiente para transformar as práticas de leitura desses profissionais, no entanto, compreendemos que cumprimos o nosso papel de problematizadores, promovendo junto aos mesmos o processo de reflexão e de preparo do terreno institucional para as transformações possíveis.

\section{Conclusão}

No decorrer desta investigação buscamos situar a leitura no processo de formação dos professores, recorrendo a uma análise geral da evolução da linguagem na humanidade, buscando situá-la como produção humana e, portanto, cercada de intencionalidades distintas.

Verificamos que o desenvolvimento da linguagem possibilitou ao homem o avanço no processo de produção e socialização do conhecimento, interferindo de forma importante nas formas como o mesmo passou a se relacionar com o tempo e com o espaço. Nesse caminho a humanidade evoluiu no sentido de sair da condição de mero decodificador das manifestações da natureza, passando a atuar como codificador de suas experiências e de suas interpretações de mundo. 
A evolução da cultura grafocêntrica marca não só a expansão das oportunidades de troca de conhecimentos e informações, mas institui a escrita como marca de exclusão social, uma vez que o domínio deste conhecimento não foi estendido a toda a população. Nesse sentido, a utilização do registro escrito, desde sua gênese, traz consigo marcas de desigualdade social.

Com o passar do tempo verificou-se uma socialização maior deste saber em decorrência da criação de escolas e da progressiva democratização do acesso da população à mesma. No entanto, as formas como a escola trabalhou este conhecimento variaram de acordo com contextos históricos e sociais e, ainda, consoante diferentes formas de compreender a própria linguagem. Dessa maneira, é possível verificar a existência de abordagens epistemológicas que vão desde aquelas que concebem o homem como um ser situado histórica e politicamente, demandando uma postura crítica diante da leitura (que não é neutra e expressa diferentes visões de mundo); assim como se podem identificar abordagens que concebem o homem como consumidor de informações e demandam deste apenas identificação dos elementos presentes na estrutura texto (concebido como uma unidade fechada sobre a qual não se podem estabelecer relações com as vivências cotidianas, tampouco confrontá-lo ou questioná-lo).

O processo de formação dos professores brasileiros traz marcas de uma perspectiva de leitura fechada, decorrente de inúmeros fatores que se somaram ao longo da história da educação e da sociedade brasileira e que tornaram os processos formativos, sobretudo os de leitura, extremamente fragilizados. Ao conhecer melhor a história dos professores fomos capazes de identificar os fatores (políticos, sociais, econômicos, culturais, etc) que interferiram de forma negativa no processo de construção identitária destes profissionais como leitores e interferir, na condição de formadores, de maneira positiva, estimulando a ampliação das visões de mundo e de experiências leitoras por meio de uma abordagem crítica dos diferentes materiais utilizados em processos de formação continuada de professores.

Que neste tempo de cobranças e críticas ao professor, os espaços de formação possam se constituir como locais de respeito aos diferentes limites 
destes profissionais e de estímulo ao potencial que cada um traz para ir além dos saberes e práticas construídos ao longo das trajetórias de formação, avançando para patamares mais conscientes e críticos acerca da leitura de seus mundos e de sua profissão.

\section{Referências}

BAKHTIN, Mikhail. Marxismo e Filosofia da Linguagem. São Paulo: Hucitec, 1998.

BARBIER, René. A Pesquisa-ação. Trad. Lucie Dídio. Brasília: Liber Livro, 2002.

BAUER, Martin W. Análise de conteúdo clássica: uma revisão. In: BAUER, Martin W.; GASKELL, George (Org.). Pesquisa qualitativa com texto, imagem e som: um manual prático. Petrópolis: Vozes, 2002.

BRASIL. Por uma política de formação de leitores. Elaboração Andréa Berenblum, Jane Paiva. - Brasília: Ministério da Educação, Secretaria de Educação Básica, 2006.

DIONE, Hugues. A pesquisa-ação para o desenvolvimento local. Trad. Michel Thillent. Brasília: Liber Livro, 2007. (Série Pesquisa).

ELLIOT, J. La Investigación - Acción en Educación. Madrid: Marata, 1990.

FRANCO, M.A.S. Pedagogia como ciência da educação. São Paulo: Papirus, 2001.

FRANCO e LISITA, Verbena Moreira Soares de Sousa. Pesquisa-ação: limites e possibilidades na formação docente. In PIMENTA, SG e FRANCO, MAS (Org.). Pesquisa em Educação: possibilidades investigativas/formativas da pesquisaação. São Paulo: Loyola, 2008.

FREIRE, Paulo. Pedagogia da autonomia: saberes necessários à prática educativa. 34 ed. São Paulo: Paz e Terra, 1996.

FREIRE, Paulo. A importância do ato de ler: em três artigos que se completam. 31.ed. São Paulo: Cortez, 1995.87p.

FREIRE, Paulo. Pedagogia da autonomia: saberes necessários à prática educativa. 34 ed. São Paulo: Paz e Terra, 1996. 
GOMES, Eduardo de Castro. A escrita na história da humanidade. Disponível em

http://dialogica.ufam.edu.br/PDF/no3/Eduardo_Aspectos_da_escrita_na_Hi storia_da_humanidade.pdf. Acesso em 10 de mar de 2009.

IMBERNÓN, F. Formação docente e profissional: formar-se para a mudança e para a incerteza. 3 ed. São Paulo: Cortez, 2002.

LAJOLO, Marisa. Do mundo da leitura à leitura do mundo. 4 ed. São Paulo: Editora Ática, 2005.

LIMA, Maria Socorro Lucena. Leitura de textos na formação de professores: transportando indagações. In LIMA, Maria Socorro Lucena; SALES, Josete de Oliveira Castelo Branco. Aprendiz da prática docente. Fortaleza: Edições Demócrito Rocha, Ed UECE, 2004. p. 26-33.

LIMA, Maria Socorro Lucena. A formação contínua do professor nos caminhos e descaminhos do desenvolvimento profissional. Tese de Doutorado. USP, 2001.

NÓVOA, António. O passado e o presente dos professores. In NÓVOA, António (Org.). Profissão professor. Porto: Porto Editora, 1995.

RIOS, Terezinha Azeredo. Compreender e ensinar: por uma docência da melhor qualidade. 7 ed. São Paulo: Cortez, 2008.

SEVERINO, Antonio Joaquim. Metodologia do trabalho científico. São Paulo: Cortez, 2000.

SILVA, Ezequiel Teodoro. $O$ ato de ler: fundamentos psicológicos para uma nova pedagogia da leitura. 10 ed. São Paulo: Autores Associados, 2008.

STENHOUSE, Lawrence. La investigación como base de la enseñanza. Madrid: Ediciones Morata, 1987.

VAZQUEZ, Adolfo Sánchez. Filosofia da Práxis. Rio de Janeiro: Paz e Terra, 1977.

VIEIRA, Sofia Lerche e FREITAS, Isabel Maria Sabino. Política Educacional no Brasil: introdução histórica. Brasília: Editora Plano, 2003.

VYGOTSKY, Lev. A formação social da mente. São Paulo: Martins Fontes, 1987.

ZAPPONE, Mirian H. Y. Práticas de leitura na escola. Tese de Doutorado. UNICAMP. Campinas, 2001. 
ZILBERMAN, R. Leitura: por que a interdisciplinaridade? In ZILBERMAN, Regina e SILVA, Ezequiel Theodoro. Leitura por que a interdisciplinaridade? In Leitura: perspectivas interdisciplinares. São Paulo: Ática, 2000

Recebido em 14 de novembro de 2016.

Aceito em 3 de dezembro de 2016. 